\title{
Risk Factors Associated with Epilepsy among Children with Cerebral Palsy
}

\author{
URMI RAHMAN ${ }^{1}$, SEIKH AZIMUL HOQUE ${ }^{2}$, AKM MATIUR RAHMAN ${ }^{3}$, NARAYAN CHANDRA SAHA ${ }^{4}$
}

\begin{abstract}
Background: Cerebral Palsy $(C P)$ is a major cause of childhood disability and is more prevalent in the more socioeconomically deprived populations of the world. Epilepsy is said to occur in 15-90\% of children with CP and this causes additional economic and psychological stress on affected children and their family.

Materials and Methods: This cross sectional case control study was conducted in paediatric neurology OPD of Dhaka Medical College Hospital \& BSMMU from July 2008 to June 2009. Four hundred children with CP were included in this study \& CP with epilepsy was taken as case and CP without epilepsy as control. Medical records of these patients were reviewed and analyzed.

Results: 150 children studied had associated epilepsy, giving a prevalence rate of $37.5 \%$. Epilepsy most commonly affected children with spastic quadriplegia (43.5\%). GTCS was more common of epilepsy in spastic quadriplegic CP and partial seizure common in spastic hemiplegic CP. After logistic regression analysis significant positive correlation was found between LBW (OR, 0.428), post-natal CNS infection (OR, 0.416 ) with occurrence of epilepsy in $C P$ cases. Statistically significant positive correlation was not found between prematurity, neonatal jaundice, neonatal convulsion, neonatal sepsis as a risk factor to develop epilepsy in CP.

Conclusion: Among CP cases epilepsy is most common in spastic quadriplegic CP and GTCS is more common type of epilepsy in spastic quadriplegic CP. LBW and postnatal CNS infection significantly increase the risk of epilepsy in CP cases. Prematurity, neonatal jaundice, neonatal convulsion does not increase the risk of developing epilepsy in $\mathrm{CP}$.
\end{abstract}

Key Words: Epilepsy, Cerebral Palsy (CP)

\section{Introduction:}

Cerebral palsy (CP) describes a group of permanent disorders of development of movement and posture, causing activity limitations that are attributed to nonprogressive disturbances that occur in developing fetal or infant brain. The motor disorders of cerebral palsy are often accompanied by disturbances of sensation, perception, cognition, communication and behavior, by epilepsy and by secondary musculoskeletal problems. ${ }^{1}$

1. Assistant Professor, Paediatrics, Popular Medical College, Dhaka.

2. Associate Professor, Paediatric Neurology, NINS, Dhaka.

3. Professor, Paediatrics, Popular Medical College, Dhaka.

4. Professor, Paediatric Neurology, NINS, Dhaka.

Correspondence: Dr. Urmi Rahman, Assistant Professor, Paediatrics, Popular Medical College, Dhaka. Mobile01716933375, email: urmirahman56@yahoo.com

Received: 30/11/2019

Accepted: $15 / 07 / 2020$
The worldwide incidence of CP is approximately 22.5 per 1000 live births. A community based study conducted by Tabib SMSB et al. during the period from July 2006 to June 2007 mentioned that the prevalence of CP was $6.1 / 1000$ children. $^{2}$

History, combined with a neurologic examination establishing diagnosis of the CP. Serial examinations may be necessary to assure the diagnosis of $\mathrm{CP}$, especially when the history is not reliable. ${ }^{3}$ Most of the CP patients also have some associated problems like epilepsy, mental retardation and problem related to speech, hearing, vision or behavior. Among them epilepsy is one of the commonest associated problem in patients of CP. ${ }^{4}$ In the general childhood population, the prevalence of epilepsy is between 3-6 per $1000 .{ }^{5}$ Epilepsy is more common in some form of CP than in others. It has been observed that seizures in the 
CP children tend to have an earlier onset, necessitating the use of more than one antiepileptic drugs. ${ }^{6,7}$ The present study aims are to observe the prenatal, natal and postnatal factors on development of epilepsy in children with CP. So, that rapid identification of patient with highest risk would allow physician to consider for early diagnosis and proper management to prevent undesirable morbidity.

\section{Materials and Methods:}

This cross sectional case control study was done in outpatient department (OPD) of Paediatric Neurology, Dhaka Medical College Hospital \& Bangabandhu Sheikh Mujib Medical University from July' 2008 to June' 2009. Total 400 hundred children with CP were included in this study and $150 \mathrm{CP}$ child with epilepsy was taken as case in group-A and $250 \mathrm{CP}$ child without epilepsy as control in Group-B. Epilepsy in suspected cases of neurometabolic and neurodegenerative disorder, whose presentation is as like as cerebral palsy and epilepsy in progressive neurological disorder were excluded. Diagnosis of cerebral palsy was clinical, based on disorder of posture and movement of cerebral origin with improving developmental trend and findings related to centers controlling such posture and movement as documented by findings related to pyramidal, extrapyramidal and cerebellar system. Epilepsy is considered to be present when two or more unprovoked seizures occur in a time frame of longer than 24 hours. Diagnosis of epilepsy was based on history from a reliable eye witness or video documentation if available and EEG was done in selected cases. All the diagnoses were made by the paediatric neurologist(s) based on study definition. Written structured questionnaire was used for collection of data regarding socio-demographic, type of $\mathrm{CP}$, type of epilepsy (where seizure present), $\mathrm{H} / \mathrm{o}$ antenatal care, gestational age, birth wt., any perinatal insult in form of asphaxia/infection/jaundice /neonatal seizure etc. Then data were analyzed to find out the associated risk factors of epilepsy using SPSS. Written informed consent was taken from parents or caregiver of each child who were enrolled in this study. Ethical approval was taken from local ethical review committee.

\section{Results:}

Among total $400 \mathrm{CP}$ children of this study, 150 children of group-A had associated epilepsy and 250 children of group-B without epilepsy. Patients age range was 6 months-9.5 years in group-A and 6 months-10 years in group-B (table-I). Maximum cases were $<2$ years of age group,52\% (78/150) in group-A and $54.4 \%$ (136/250) in group-B. Male cases were more, 60\% (90/150) in group-A and 56.4\% (141/ 250 ) in group $B$ (table-I). In group-A home delivery was more (54\%) but in group-B hospital delivery were more $(52 \%)$. On the other hand, normal vaginal delivery was more than caesarean section in both group (table-II). Considering the type of CP spastic quadriplegia was found as most common type in both group, 48\% (72/150) in group-A and 40.8\% (102/250). Spastic Diplegia was second most common type of CP in both group (22\% in group-A \& $25.6 \%$ in groupB).Other than motor delay speech delay was the most common in both group 50\% (75/150) in group-A and $47.6 \%(119 / 250)$ in group-B. Considering common risk factors causing $\mathrm{CP}$, LBW was the commonest risk factor in group-A (42\%) and delayed cry was the commonest in group-B (35.6\%) (table-III) in CP cases. In this study among CP cases epilepsy was found in $37.5 \%$ (150/400).

Table I

Age \& sex distribution of patients $(n=400)$

\begin{tabular}{lcc}
\hline Age in Year & Group A $(n=150)$ & Group B $(n=250)$ \\
\hline$<2$ & $78(52 \%)$ & $136(54.4 \%)$ \\
$2-5$ & $63(42 \%)$ & $93(37.2 \%)$ \\
$>5$ & $9(6 \%)$ & $21(8.45)$ \\
Mean $\pm S D$ & $2.39 \pm 2.07$ & $2.44 \pm 1.98$ \\
Sex & & \\
$\quad$ Male & $90(60 \%)$ & $141(56.4 \%)$ \\
$\quad$ Female & $60(405)$ & $109(43.6 \%)$ \\
\hline
\end{tabular}

Table II

Place and mode of delivery of patients ( $n=400)$

\begin{tabular}{lccccc}
\hline Place of & \multicolumn{2}{c}{$\begin{array}{l}\text { Group A } \\
\text { delivery }\end{array}$} & \multicolumn{2}{c}{ Group B } & p \\
& $n=150)$ & \multicolumn{2}{c}{$(n=250)$} & value \\
& $n$ & $\%$ & $n$ & $\%$ & \\
\hline Home & 81 & 54 & 120 & 48 & 0.245 \\
Hospital & 69 & 46 & 130 & 52 & \\
Mode of delivery & & & & & \\
NVD & 111 & 74 & 188 & 75.2 & 0.789 \\
CS & 39 & 26 & 62 & 24.8 & \\
\hline
\end{tabular}


Table III

Comparison of risk factors in studied children $(n=400)$

\begin{tabular}{|c|c|c|c|c|c|}
\hline \multirow[t]{2}{*}{ Risk factors } & \multicolumn{2}{|c|}{ Group $A(n=150)$} & \multicolumn{2}{|c|}{ Group B(n=250) } & \multirow[t]{2}{*}{ pvalue } \\
\hline & $\mathrm{n}$ & $\%$ & $\mathrm{n}$ & $\%$ & \\
\hline ANC (absent) & 54 & 36 & 87 & 34.8 & 0.808 \\
\hline Maternal illness & 15 & 10 & 37 & 14.8 & 0.167 \\
\hline LBW & 63 & 42 & 79 & 31.6 & 0.035 \\
\hline Prematurity & 24 & 16 & 49 & 19.6 & 0.367 \\
\hline Delayed Cry & 48 & 32 & 89 & 35.6 & 0.463 \\
\hline Neonatal Jaundice & 31 & 20.7 & 34 & 13.6 & 0.064 \\
\hline Neonatal Sepsis & 25 & 16.7 & 30 & 12 & 0.189 \\
\hline Neonatal Convulsion & 54 & 36 & 63 & 25.2 & 0.016 \\
\hline Postnatal CNS infection & 16 & 10.7 & 11 & 4.4 & 0.016 \\
\hline
\end{tabular}

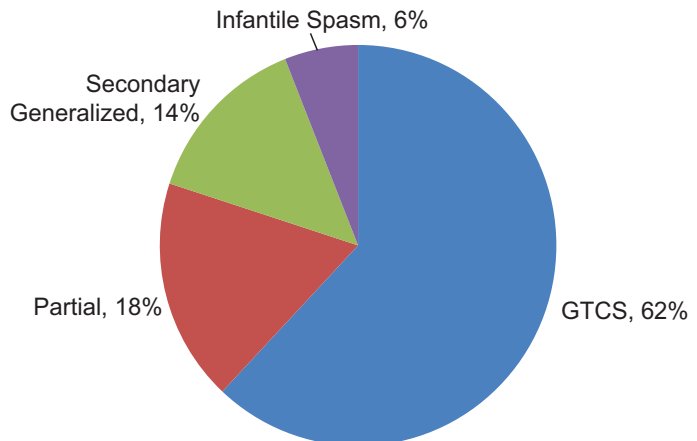

Fig-1: Type of epilepsy in children having epilepsy $(n=400)$

In CP with epilepsy (group-A, 150 cases) $73.3 \%$ (110/ 150 ) of children manifested first seizure before one year of age and GTCS was the most common type of seizure $62 \%$ and partial seizure was found in $18 \%$ cases (Figure-1). GTCS was the commonest type of seizure in spastic quadriplegic CP and partial type in spastic hemiplegic CP (Figure-2).

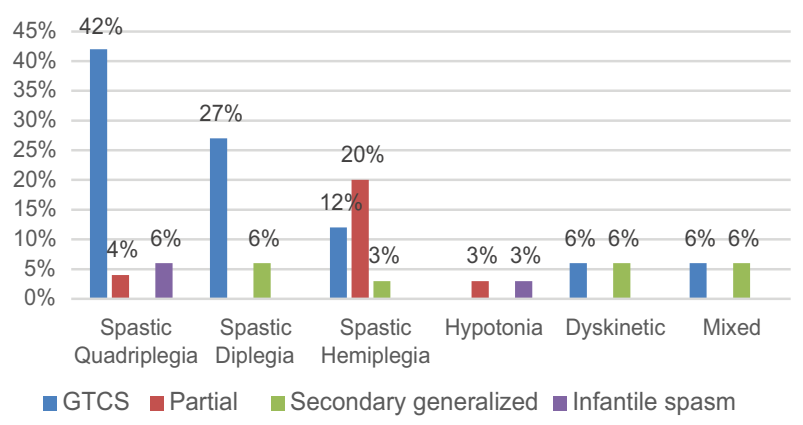

Fig.-2: Seizure pattern in different type of $C P(n=150)$

By calculating Odds ratio by logistic regression analysis (Table-IV) it was found that LBW and postnatal CNS infection significantly increase the risk of epilepsy in CP cases. It was also found that prematurity in CP cases is an important factor which reduce the risk of epilepsy significantly.

Table IV

Logistic regression analysis of epilepsy on predictor variables

\begin{tabular}{lccc}
\hline Variable & Adjusted Odds ratio (OR) & $95 \% \mathrm{Cl}(\mathrm{OR})$ & $\mathrm{p}$ value \\
\hline ANC (absent) & 1.250 & $0.766-2.038$ & 0.372 \\
Maternal illness & 1.321 & $0.660-2.645$ & 0.432 \\
LBW & 0.428 & $0.42-0.757$ & 0.004 \\
Prematurity & 2.296 & $1.097-4.806$ & 0.027 \\
Delayed Cry & 1.149 & $0.708-1.864$ & 0.575 \\
Neonatal Jaundice & 0.830 & $0.450-1.532$ & 0.551 \\
Neonatal Sepsis & 0.778 & $0.400-1.513$ & 0.459 \\
Neonatal Convulsion & 0.726 & $0.40-1.170$ & 0.188 \\
Postnatal CNS infection & 0.416 & $0.171-1.014$ & 0.05 \\
\hline
\end{tabular}




\section{Discussion:}

In this study epilepsy was present among $37.5 \%$ of children with $\mathrm{CP}$, which is similar to other studies of Laganju IA, Kulak W, Carlsson M, Hadjipanayis A and Zelnik $\mathrm{N}$ etal. where frequencies $29 \%-42 \%$ have been reported. ${ }^{8-12}$

In this study, home delivery was found more among $\mathrm{CP}$ with epilepsy and hospital delivery was more in $\mathrm{CP}$ without epilepsy. On the other hand, normal vaginal delivery was more than cesarean section in both groups of CP, which is similar to observations of Lagunju IA. ${ }^{8}$ and Kulak W. ${ }^{9}$ in their study.

In this study spastic quadriplegic type of $\mathrm{CP}$ was more common in both group followed by spastic diplegia. Kulak W. ${ }^{9}$ and Hadjipanayis $A .{ }^{11}$ found similar result in their study.

In this study, the first seizure occurred during the first year of life in $73.33 \%$ of patient of group A (CP with epilepsy) which is similar with observation of Kulak $\mathrm{W} .{ }^{9}$ and Nathanel $\mathrm{N}$ et al. ${ }^{12}$ in their study. The most common forms of seizure found in children with $\mathrm{CP}$ in this study were GTCS $(62 \%)$, partial $(18 \%)$, secondary generalized (14\%) and less common forms seen was infantile spasm (6\%). This finding was consistent with report from previous studies of Lagunju IA. ${ }^{8}$ as they found major seizure types were GTCS $(53.8 \%)$, partial seizure $18.5 \%$ and infantile spasm $15.4 \%$.

The findings of the present study showed that epilepsy was more likely to have in children with quadriplegic CP. Similar result have been reported by Kwng M. ${ }^{4}$ and Carlsson A. ${ }^{10}$ in their studies.

In this study LBW was found more frequently (42\%) in CP with epilepsy and was significantly associated with an increased risk of epilepsy. Kulak W. ${ }^{9}$ and Curatolo P. ${ }^{13}$ also found association between LBW and increased risk of epilepsy in $C P$ cases. Prematurity was present in $16 \%$ in group-A and $19.6 \%$ in group-B in this study but after logistic regression analysis no significant positive correlationwas found to develop epilepsy in CP. Hirvonen $\mathrm{M}$ etal. ${ }^{14}$ in their study among CP cases found preterm birth was associated with a significantly increased risk of epilepsy which differ from our study.

Postnatal CNS infection showed significant relation to develop epilepsy in CPin this study, which is similar to findings of Lagunju IA. ${ }^{8}$ andCarlsson M. ${ }^{10}$ in their study. This study showed no significant relation between neonatal convulsion and development of epilepsy in $\mathrm{CP}$ cases, that observation was similar to Kwong K. ${ }^{4}$ and Zelnik $\mathrm{N}$ et al. ${ }^{12}$ in their study.

There were some limitationsas it was a retrospective study. It is assumed that a prospective approach would have resulted in more comprehensive data retrieval. Familial history of epilepsy previously noted to be a significant risk factor for epilepsy among children with CP and epilepsy ${ }^{13,15}$ has not been included in our analysis (due to difficulties to validate its reliability). Further studies looking in to possible genetic and early prenatal factors may lead to better understanding of the cause of epilepsy.

\section{Conclusion:}

Among CP cases epilepsy is most common in spastic quadriplegic CP and GTCS is more common type of epilepsy in spastic quadriplegic CP. LBW and postnatal CNS infection significantly increase the risk of epilepsy in CP cases. Prematurity, neonatal jaundice, neonatal convulsion, neonatal sepsis does not increase the risk todevelop epilepsy in CP.

\section{References:}

1. Peter Rosenbaum, Nigel Paneth, Alan Leviton, Murray Goldstein, Martin Bax, Diane Damiano et al. A report: the definition and classification of cerebral palsy April 2006. Dev Med Child Neurol Suppl. 2007;109:8-14.

2. Tabib SMSB, Khatoon S, Hassan MQ, Baki AE, Rahman AKMF. Prevalence of childhood disabilities and cerebral palsy in the community. In: Banu NA, Shamsad IA, Khan NZ, Haque MM, Ferdous S (editors). First National Conference 2008, March 17-19, Bangladesh society for child neorology, development and disability. Bangladesh College of Physician \& Surgeons (BCPS), Mohakhali, Dhaka.

3. Ashwal S, Russman BS, Blasco PA, Miller G, Sandler A, Shevell $M$ et al. Practice Parameter: Diagnostic assessment of the child with cerebral palsy: Report of the Quality Standards Subcommittee of the American Academy of Neurology and the Practice Committee of the Child Neurology Society. Neurology 2004; 62:851-63.

4. A.K. Gururaj, L. Sztriha, A. Bener, A. Dawodu, V. Eapen. Epilepsy in children with cerebral palsy. Seizure 2003; 12 : 110-14

5. Forsgren L. Epidemiology: Incidence and prevalence. In: Wallace S, editor. Epilepsy in children. London: Chapman and Hall 1996: 27-37.

6. Aksu F. 'Nature and prognosis of seizures in patients with cerebral palsy. Dev Med Child Neurol, 1990:32; 661-8.

7. Delgado MR, Riela AR, Mills J, Pitt A, Brone R. Discontinuation of antiepileptic drug treatment after two seizure free years in children with cerebral palsy. Pediatrics 1996: 97; 192-97. 
8. Lagunju IA, Adedokun BO, Fatunde OJ. Risk factors for epilepsy in children with cerebral palsy. African Journal of Neurological Sciences 2006;25:19-37.

9. Kulak W, Sobaniec W. Risk factors and prognosis of epilepsy in children with cerebral pals in north-eastern Poland. Brain and Dev 2003;25:499-506

10. Carisson M, Hagberg G, Oisson I. Clinical and aetiological aspects of epilepsy in children with cerebral palsy. Dev Med Child Neurol 2003;45(6): 371-6.

11. Hadjipanayis A, Hadjichristodoulou C, Youroukos S. Epilepsy in patients with cerebral palsy. Dev Med Child Neurol. 1997:39: 659-63.
12. Zelnik N, Konopnicki M, Bennett-Back O, Castel-Deutch $\mathrm{T}$, Tirosh E. Risk factors for epilepsy in children with cerebral palsy. Eur J Paediatr Neurol. 2010;14:67-72.

13. Curtalo P, Arino C, Stazi MA, Medda E. Risk factors for the occurance of partial epilepsy, cerebral palsy and mental etardation. Dev Med Neurol. 1995;37: 776-82.

14. Hirvonen M, Ojala R, Korhonen P, Haataja P, Eriksson K, Gissler M, Luukkaala T, Tammela O. The incidence and risk factors of epilepsy in children born preterm: A nationwide register study. Epilepsy Res. 2017;138:32-38.

15. Arpino C, Curatolo P, Stazi MA, Vlahov D. Differing risk factors for cerebral palsy in the presence of mental retardation and epilepsy. J Child Neurol. 1999; 14:151-5. 